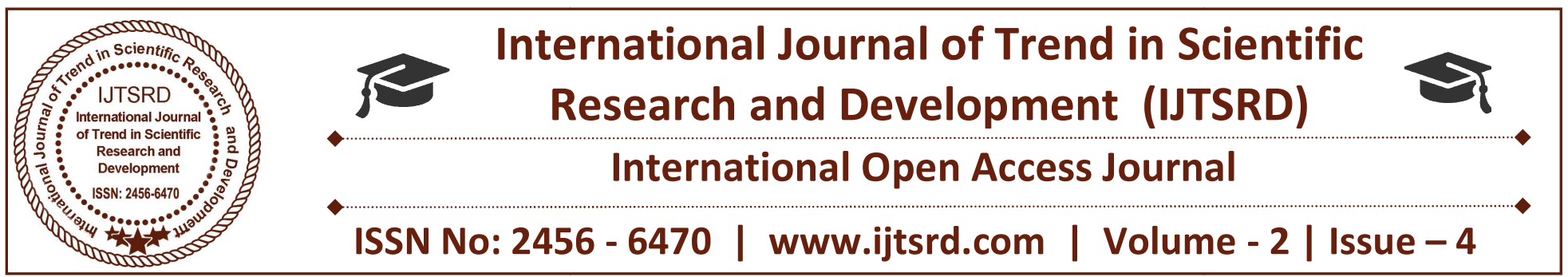

\title{
Comparative Analysis \& Design of Regular \& Irregular Building \& its Behaviour at Different Earthquake Zone by Using Etabs \& Redc Software
}

\author{
Vedantee Prasad Shukla, Sayali Pradeep Rote, Manoj Bharat Kamble \\ Department of Civil Engineering, SAOE (Kondhwa), Pune University, Pune, Maharashtra, India
}

\begin{abstract}
In civil structure static analysis is perform for R.C.C frame regular and irregular building upto $\mathrm{G}+15$ storey by using "Response Spectrum Method". The problems introduced due to discontinuity in stiffness, mass and geometry of structure.IS codes are used for design of various civil engineering structures and their specification. These elements are designed by using software ETABS. And consider seismic load and wind load. For load combination use code IS 1893:2002. Irregular building is compared in all four zones. The designing has been carried out in ETABS software (software that deals with analysing and designing of structures. This software is easy to understand for user). All the building structure and modelled analysed and then designed for all four zones. All model are analysis in ETABS software and design in RCDC software and their results are obtained in all seismic zones. The base shear force, volume of concrete, weight of steel and cost effectiveness have been calculated to depict all the differences in structure behaviour when analysed and design in all four zones by using ETABS and RCDC software.
\end{abstract}

Keywords: Static analysis, base shear, time period, storey drift

\section{INTRODUCTION}

When earthquakes occur, a buildings undergoes dynamic motion. Due to that inertia forces are generated. These inertia forces, called seismic loads.

Here we are going to analyze of static analysis up to G+15 R.C. frame building at different earthquake zone.
Static loads are the loads which varies very slowly (the acceleration of load is very less than the natural frequency of structure.

In the recent days the tall structure has more demand for the construction, the building must withstand against lateral force acting on the structure due to the natural calamities such as the earth quake and may also be wind load so in this project the comparative studies is done for the different zone by providing the required size of the columns and beams by following Indian standards If the design is not in a proper way means the sudden effect of earthquake may cause the structural collapse and life of people may spoil. So it may cause homeless to common people. So it is a major task to design structure in a proper way. The structure which performs against the earthquake means structure must possess the simple, regular configuration and minimum lateral strength and also stiffness of the structure.

\section{LITERATURE REVIEW:}

1. Gagandeep ${ }^{1}$, Himanshu Bansal ${ }^{2}$ researched on to carry out Time History analysis (THA) and Response Spectrum Analysis (RSA) of ductility and vertically irregular building $\mathrm{RC}$ frames. Three types of irregularities were considered namely stiffness irregularity, mass irregularity and vertical geometry irregularity.

2. Dinesh W. Gawatre research on to calculate a shear generated due to torsion in the columns \& to understand torsional response \& different irregularity due to plan and to analyze L shape and cross shape building during occurrence of earthquake forces . 
3. Priyabrata ${ }^{1}$ Arunava $^{2}$ research on earthquake occurrence \& suggest preventive measures to overcome earthquake. In this paper study is made to find response of irregular and regular structures with the help of nonlinear dynamic and static analysis.

4, Sourav Ray1, Amit Chakraborty2, Mohammad Elias1, research on to achieve better performance from RCC structure. In this paper study on, Wshape, L-shape, Rectangle, Square are four different shaped ten storied RCC building frames and their analysis using ETABS v9.7.1 and SAP 2000 v14.0.0 for seismic zone 3 in Bangladesh. The results obtained from the response spectrum analysis that the displacements for regular shaped building frames are less than that of irregular shaped building.

5. Hema Mukundan1, S.Manivel2 research on Dynamics in structure \& their study has been slowly increasing over the long period of years. Mostly present trend is towards slender and tall structures (Irregular) and architecturally designed structures like the temple (Lotus shaped).

6. Mamathashree K.S1, Sanjay S.J2 research on generation of effect of soil structure and irregularity are the main factors for the mega structures which are resting on highly flexible soil. In the conventional design process generation of effect due to soil structure interaction is neglected, flexibility of soil is directly proportional to natural period which reduces the base shear. In this paper study related to the seismic response of $\mathrm{RC} /$ special moment resisting frame buildings of 4,8,12 storey regular and irregular structure resting on different types of soil, by using linear response spectrum analysis with and without soil structure interaction effect and also research on the seismic behavior of mass, stiffness.

\section{AkhilaLekshmi N H1, Aswathy S. Kumar2} research on by using steel bracing has advantage over oscheme like higher strength and stiffness, economical, occupies less space, adds much less weight to existing structure. For this purpose response spectrum method is carried out and their results are obtained in ETABS.

8. Arun Solomon A1, Hemalatha G2 1 research on find accurate \& to understand result in drift, deflection and hinge of structure under seismic force and non Linear Static Analysis. This analysis method shows the base shear carrying capacity and performance level of component of structure under different zones or different intensity. The present study is carried out on to find the non linear behavior of irregular structures. Because of the constraints some of the structures are highly irregular as too long and too tall.

\section{METHODOLOGY:}

\section{Building Considered for the Analytical Study}

For present work seismic analysis is carried out for reinforced concrete moment resisting building frame having (PLINTH $+\mathrm{G}+15)$ storey situated in zone II, III, IV,V for ground slope greater than 3degree. Analysis \& design are carried out by using ETABS \&RCDC software.

Four types of buildings considered in the study, which are

- Regular building without shear wall

- Regular building with shear wall

- Irregular building without shear wallI

- rregular building with shear wall

PLAN OF REGULAR BUILDING WITHOUT SHEAR WALL
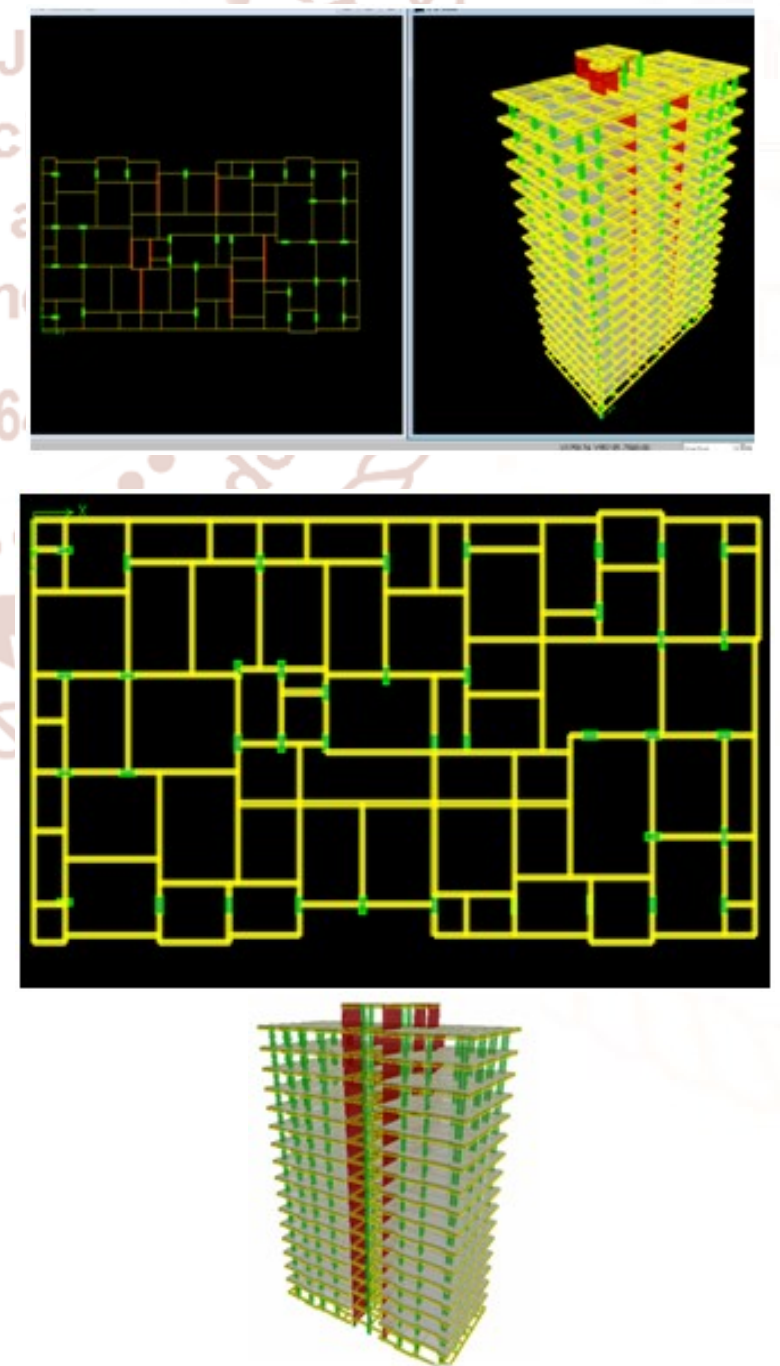

3-D View of regular building with shear wall 


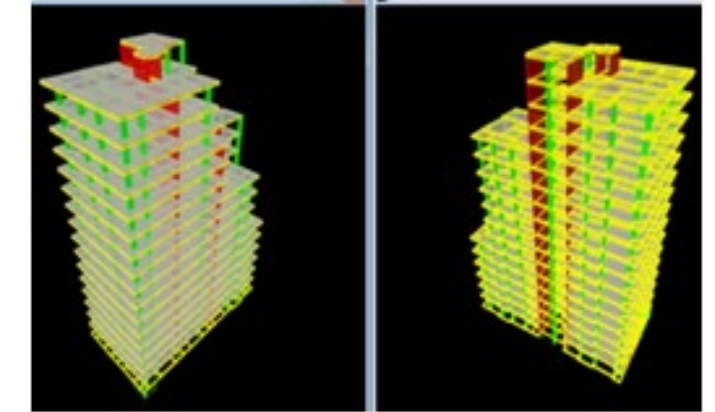

3D VIEW OF IRREGULAR BUILDING
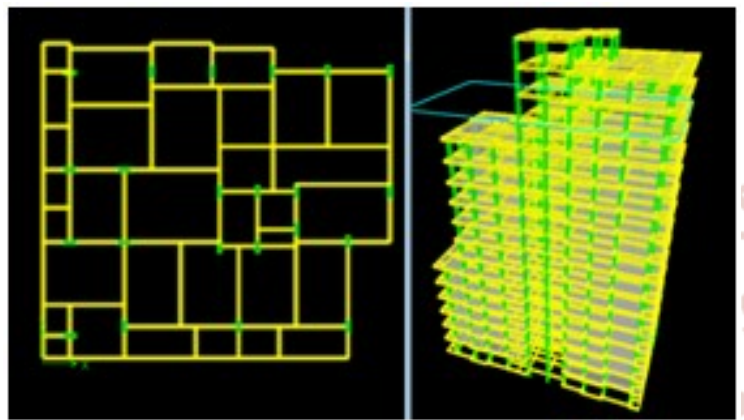

IRREGULAR BUILDING PLAN WITHOUT SHEARWALL@10 ${ }^{\mathrm{TH}}$ STOREY
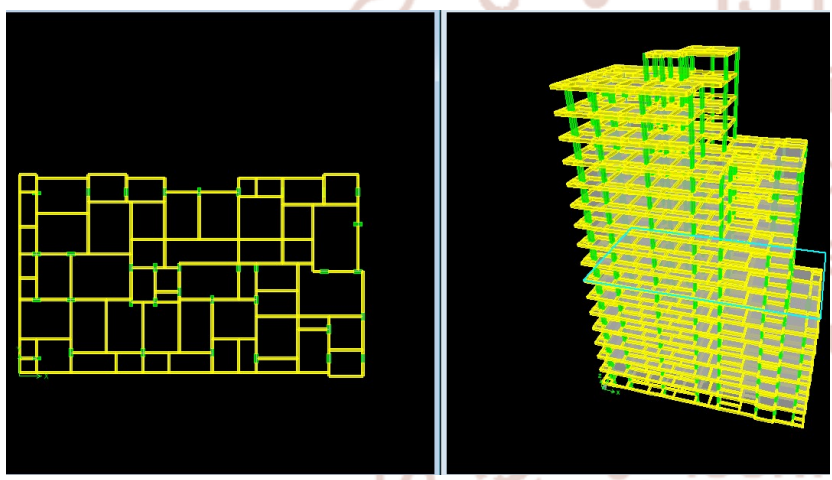

IRREGULAR BUILDING PLAN WITHOUT SHEAR WALL@6th STORY

Graph-4.3 shows the values of Story shear in EQX \& EQY direction for Irregular Building.

Graph -4.4 shows the values of Story drift in EQX \&EQY direction for Regular Building.

Graph -4.5 shows the values of Story drift in EQX \& EQY direction for Irregular Building.

Graph-4.6-show the value of requirement of steel quantity in regular and irregular building in all earthquake zone

Design of column with response spectrum method

Graph-4.1 shows the values of Time period for

Regular \& Irregular building

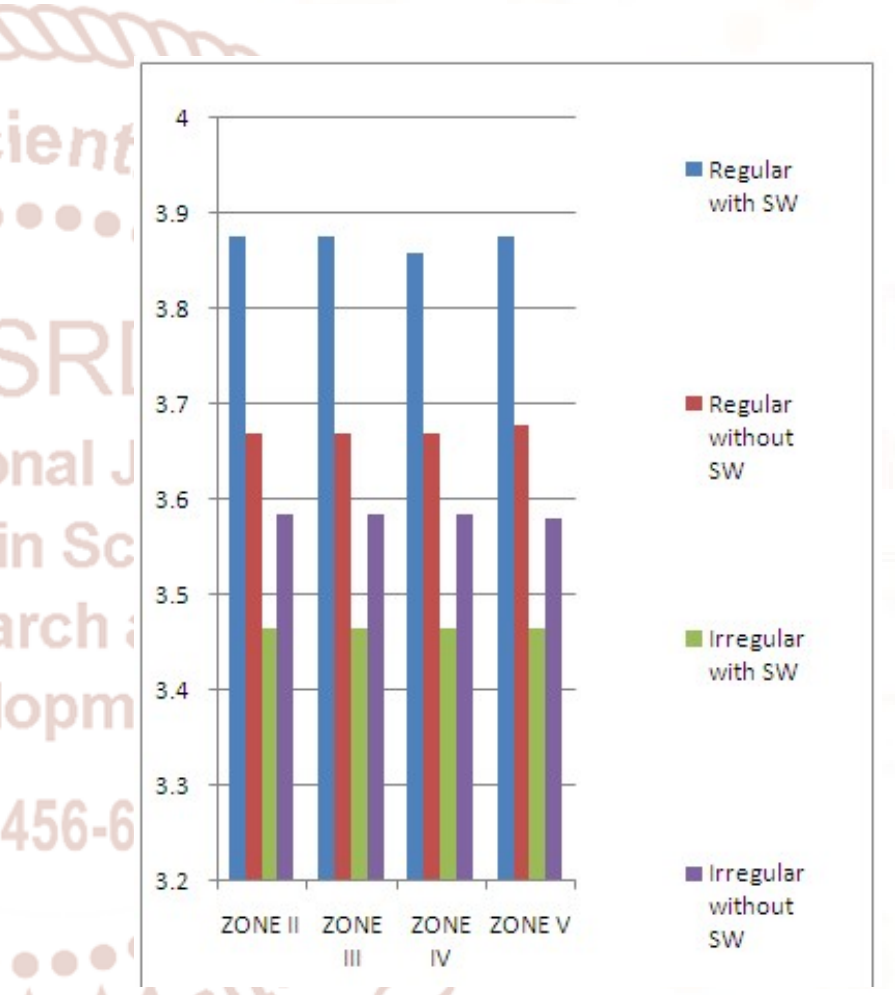

\subsection{Analytical Analysis}

The response spectrum analysis and nonlinear static analysis with response spectrum method is carried out for both types of building models i.e. buildings with and without shear wall of regular \& irregular building as mentioned in the previous chapter and results are shown graphically. Graph 4.1 to 4.5 Graph shows the results of response spectrum analysis

The results are shown graphically which are listed below:

A) Regular\& Irregular Buildings analyzed with \&without shear wall.

Graph-4.1 shows the values of Time period for Regular \& Irregular building.

Graph -4.2 shows the values of Story shear in EQX \& EQY direction for Regular Building. 
International Journal of Trend in Scientific Research and Development (IJTSRD) ISSN: 2456-6470

Graph -4.2 shows the values of Story shear in EQX \&

EQY direction for Regular Building

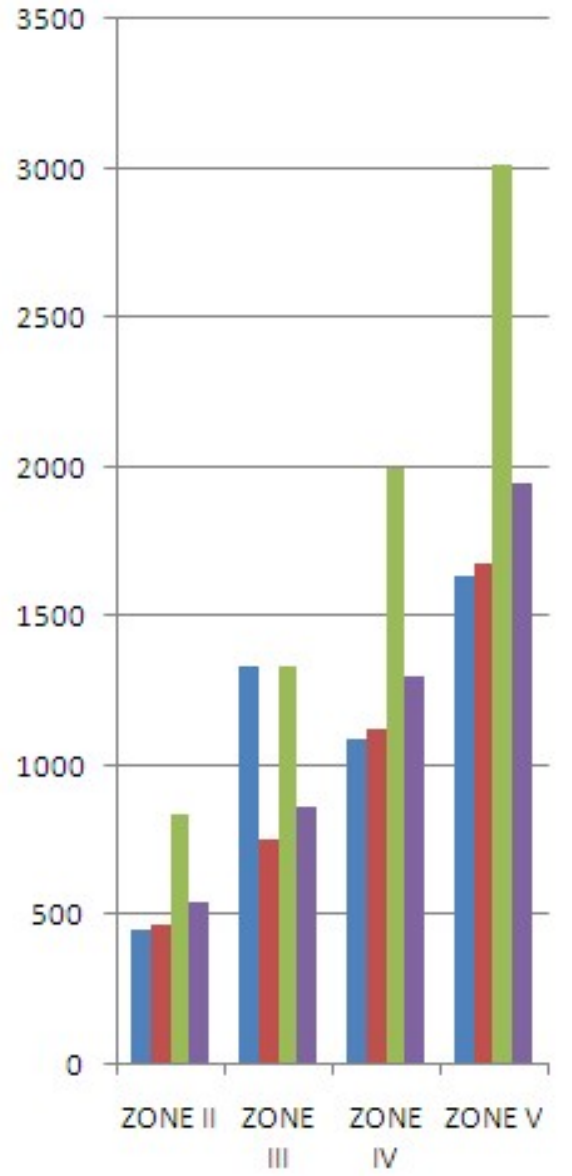

Graph -4.3 shows the values of Story shear in EQX \& EQY direction for Irregular Building

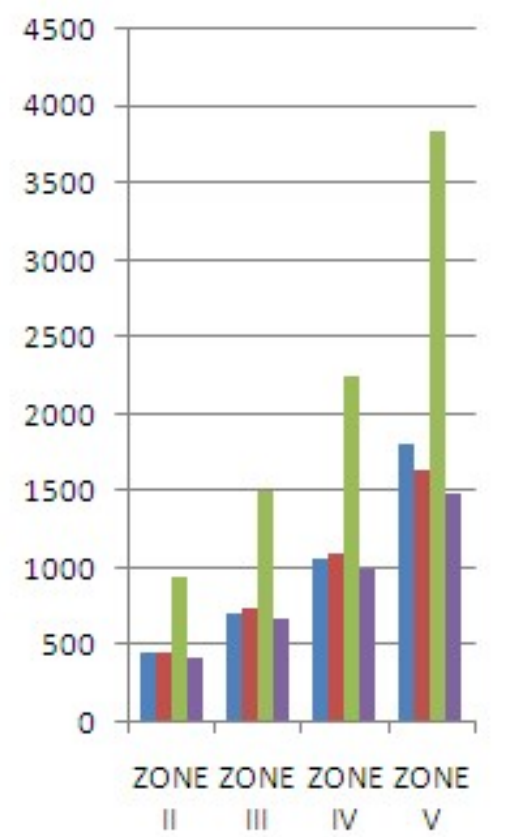

Graph -4.4 shows the values of Story drift in EQX \&EQY direction for Regular Building

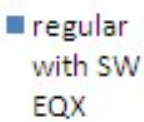

n regular without SW EQX

regular EQY

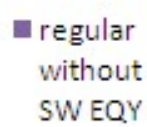

arregular with SW IN EQX

- irregular without SW IN EQX

- irregular with SW IN EQY

irregular without SW IN EQY with SW

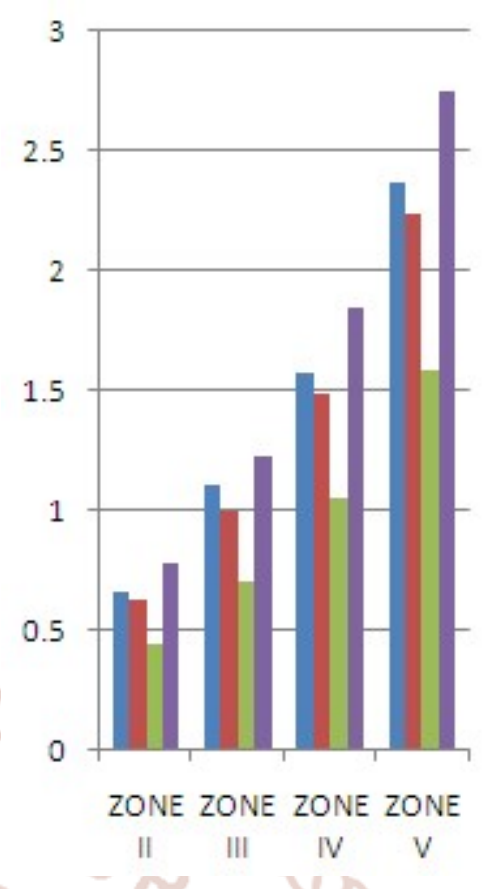

- Regular building with SW EQX

- Regular building without SW EQX

- Regular building with SW EQY

- Regular building without SW EQY

Graph -4.5 shows the values of Story drift in EQX \& EQY direction for Irregular Building

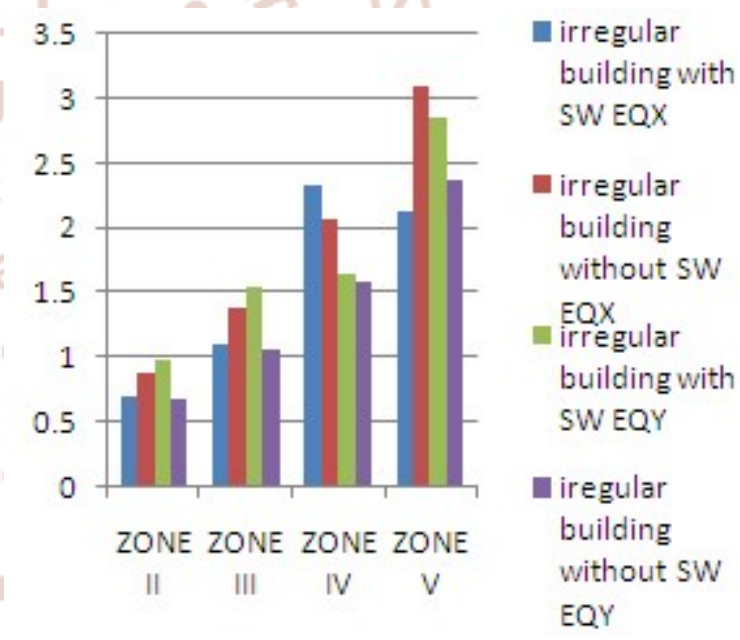

Graph-4.6-show the value of requirement of steel quantity in regular and irregular building in all earthquake zone

STEEL ANALYSIS

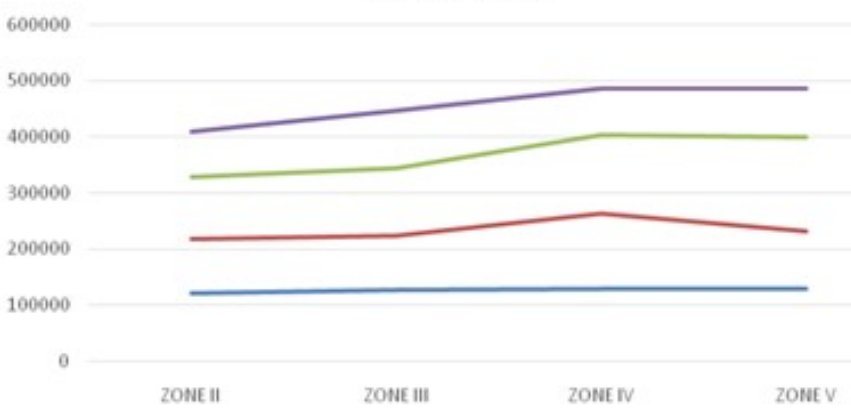

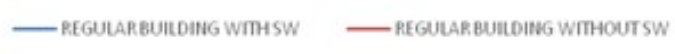

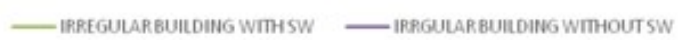


CONCLUSION:

$>$ Results in the form of storey displacement, storey drift, base shear and time period.

$>$ Time period of the regular building is more than irregular.

$>$ Base shear in the EQX of the irregular building is more than regular building.

$>$ Base shear in the EQY of the irregular building is more than regular building.

$>$ Story drift in EQX direction of the regular building is less than the irregular building.

$>$ Story drift in EQY direction of the regular building is less than the irregular building.

$>$ As per the graph 4.6 zone IV \& V are the more severe zones. They required more steel to resist the earthquake force and they also required shear wall at the mid of the building.

\section{Future Scope:}

A lot of research work is taking place in the globe to study the seismic behavior of Regular and Irregular building with and without shear wall at all earthquake zone.

Following are the some points for future scope of this study:

1. The seismic analysis of buildings on hills and effect on elements surrounding elements using dynamic analysis can be done.

2. The detailed study of effects of slopes on earthquake parameters can be studied.

3. The effect soil conditions on construction of a building on hills can be studied.

\section{REFRENCES:}

1. "Comparative Study of Multi-storey Reinforced Concrete Framed Structures And Its Seismic Behaviour, Young Lu.

2. "Comparative Study of Multi-Storey Irregular Building And Its Static \&Dynamic Analysis, Ehsan Salimi Firozabad.

3. "Seismic analysis of RC irregular and regular frame structures, R.J. Fernandes.

4. Seismic Analysis and Design of Vertically Irregular RC Building Frames, Sharma, A

5. Comparative Study of Seismic Performance of Building Having Mass Vertical Irregularity at Different Floor Levels, Kumar, M. and V. G. Babu.

6. Response of multi-storey regular and irregular buildings of identical weight under static and dynamic loading in context of Bangladesh, Kabir, R., D. Sen, and M. Islam.

7. M. M. Islam, Analysis on the structural systems for drift control of tall buildings due to wind load: critical investigation on building heights. The AUST Journal of Science and Technology, 2014

8. Comparison of Practical Approaches for Modelling Shear walls in Structural Analyses of Buildings, M.T.T \& Y. M. Fahjan .

9. "Practical Modelling Aspects for Analysis of Shear walls using Finite Element Method, W. A. Thanoon, H.H Hamzah.

10. Qualitative Response of Seismic Response of Vertically Irregular Building Frames, Bharat B. Mistry. 